\title{
RELATOS DE HISTÓRIAS DE CASAIS NO CHILE ATUAL: A INTIMIDADE COMO UM MONÓLOGO COLETIVO'
}

\author{
Dariela Sharim* \\ Claudia Araya \\ Mariela Carmona \\ Paula Riquelme ${ }^{\Phi}$
}

\begin{abstract}
RESUMO. Importantes mudanças no âmbito da intimidade têm sido descritas à luz dos processos de individualização social. Dentro desse marco, a presente pesquisa indaga a respeito das relações de casais nos significados e na experiência subjetiva, tendo como foco a dimensão psicológica da intimidade. Foram coletados relatos de casais de homens e mulheres adultos chilenos que narraram sua vida de casal. O pressuposto da relação de casal como emblemática do espaço da intimidade vê-se questionado pelos resultados. Os narradores não falaram de intimidade quando se referiram à vida de casal, mas transmitiram um sentimento de medo ou ameaça, e de evitação da entrada do outro nesse espaço. De seus relatos se depreende que os ideais de casal, paradoxalmente, são constuídos de forma individual, constituindo-se numa maneira de ser em casal que denominamos "monólogo coletivo".
\end{abstract}

Palavras-chave: Intimidade; história de vida; individualização.

\section{NARRATIVES OF COUPLE HISTORIES IN CHILE TODAY: INTIMACY AS A COLLECTIVE MONOLOGUE}

\begin{abstract}
Important changes in the realm of intimacy have been described in light of the processes of social individualization. In this context, this research enquires the meanings and subjective experience regarding couple relationships, focusing in the psychological dimension of intimacy. Life histories from Chilean adult men and women who narrated their couple's history were collected. The results call into question the assumption that this relationship is particularly representative of the domain of intimacy. When talking about couples the interviewees did not talk about intimacy. Instead, they conveyed a sense of fear or threaten, and the avoidance of the other in that realm. Their narratives show that the ideals regarding the couple are -paradoxically- constructed at an individual level, and this results in a way of being in a couple's relationship that we have called "collective monologue".
\end{abstract}

Key words: Intimacy; life stories; individualization.

\section{RELATOS DE HISTORIAS DE PAREJA EN EL CHILE ACTUAL: LA INTIMIDAD COMO UN MONÓLOGO COLECTIVO}

RESUMEN. A la luz de los procesos de individualización social, se han descrito importantes cambios en el ámbito de la intimidad. En este marco, esta investigación indaga en los significados y en la experiencia subjetiva respecto a las relaciones de pareja, focalizándose en la dimensión psicológica de la intimidad. Se recogieron relatos de vida de hombres y mujeres adultos chilenos, quienes narraron sus historias de pareja. El supuesto de esta relación como emblemática del espacio de

\footnotetext{
1 Apoio: Vicerrectoría Adjunta de Investigación y Doctorado (VRAID) de la Pontificia Universidad Católica de Chile (Proyecto Límite $\left.\mathrm{N}^{\circ} 14 / 2009\right)$.

Psicóloga, Phd en Université Catholique de Louvain-la-Neuve. Profesora Asociada, Escuela Psicología Pontificia Universidad Católica de Chile.

I Psicóloga, Máster en University of Kent. Profesora Asistente, Escuela Psicología Pontificia Universidad Católica de Chile.

æ Psicóloga, Phd. Pontificia Universidad Católica de Chile.

Ф Psicóloga, Máster Universidad de Chile.
} 
intimidad, se ve cuestionado por los resultados. Al hablar de pareja, los narradores no hablaron de intimidad. Transmitieron más bien un sentimiento de temor o amenaza y la evitación del otro en este espacio. De sus relatos se desprende que los ideales de pareja se construyen paradojalmente de manera individual, instalándose una manera de ser en pareja que hemos denominado "monólogo colectivo".

Palabras-clave: Intimidad; relatos de vida; individualización.

Es posible observar hoy en las sociedades occidentales importantes cambios y transformaciones en las formas de constituir pareja, como también en los significados y objetivos sociales de la unión de dos personas (Beck \& Beck-Gernsheim, 2003; De Cristóforis, 2009; Singly, 2005; Giddens, 1992; Luhmann, 1985; Moreno, 2008; Sharim, 2005). La sentimentalización de la vida privada (Ariès, 1973), característica de la modernidad, trajo consigo la legimitización del sentimiento amoroso y de la libre elección como criterios fundamentales para la formación de una pareja (Aboim, 2006, 2009). De esta forma, a partir del siglo XVIII y sobrepasando la tradicional subordinación de la unión conyugal a los intereses económicos y sociales de reproducción familiar, el amor se instaura poco a poco como un sentimiento esperado entre los cónyuges. El "matrimonio por amor" finalmente se constituye como norma a comienzos del siglo XX (Bozon, 2010). Surge así un ideal de pareja nuclear, dependiente y fusional, organizado claramente en torno a la división sexual del trabajo (Aboim, 2006, 2009). Se cristaliza aquí la figura del amor romántico -aún reconocible en nuestros días- y la idealización del objeto de amor. Se destaca así la importancia de los afectos en la constitución de una pareja y se la legitima como un vínculo que se constituye en un lugar de refugio y de intimidad (Costa, 2007).

En nuestros días, la alianza íntima entre dos personas cobra nuevos sentidos frente a un mundo fuertemente exigente, individualizado y demandante en relación a la búsqueda de autonomía personal. Los espacios de apoyo mutuo y de solidaridad parecen ser todavía altamente valorados (Lipovetsky, 2000). Desde la teoría social, la reflexión acerca de la individualización se ha configurado entonces como un elemento importante de considerar al momento de interpretar las transformaciones en la esfera de las relaciones de pareja (Luhmann, 1985; Moreno, 2008). El fenómeno de la individualización sería la expresión de cambios socio-culturales ocurridos desde la mitad del siglo $\mathrm{XX}$, en que los individuos pasarían desde un contexto de fuerte supeditación a las instituciones, con roles establecidos y fijos, a otros en que deben construir por sí mismos su propia identidad (Beck \& Beck-Gernsheim, 2003; Ehrenberg, 2000; Moreno,
2008). Asimismo, elegir vivir con un otro sería hoy una opción libre y personal, no supeditada - en apariencia, como veremos más adelante - a las demandas sociales y culturales acerca de lo que se espera de una pareja. Se trataría de un proyecto de a dos, que no acepta la intromisión de terceros. De esta forma, en las relaciones de pareja, el aumento de la autonomía y de los recursos personales para elaborar reflexivamente la propia identidad, produciría formas de relacionamiento más horizontales, caracterizándose la pareja contemporánea por la referencia al sentimiento amoroso y la valoración de la atracción sexual, además de la importancia de los proyectos individuales en el contexto de la relación de pareja (Moreno, 2008). La figura del amor romántico estaría dando paso a otras formas de amor. Giddens (1992) ha llamado "amor confluente" al amor que no aspira a la fusión ni a la disolución de las individualidades de sus miembros, sino que permite mantener la propia identidad personal (De Cristóforis, 2009; Moreno, 2008). Se trataría desde ahora de la búsqueda de una relación "pura", más democrática, basada fundamentalmente en una intimidad que contempla la comunicación emocional y las recompensas derivadas de ella (Giddens, 1992).

Sin embargo, al menos en nuestros países latinoamericanos, el ideal del amor confluente pareciera coexistir con la visión - en algunas ocasiones hegemónica y en otras algo transformada - del amor romántico. Las personas enfrentarían todavía contradicciones asociadas a la aparente paradoja entre la búsqueda de libertad individual y las gratificaciones amorosas de una vida de a dos, entendidas aún a partir de un ideal romántico. Se instala así una tensión entre autonomía e intimidad. Pese a esto, la vida en pareja sigue siendo en nuestros días deseada. En Chile, según datos entregados por el PNUD (2002), la relación de pareja cobra cada vez más importancia en el repertorio de vínculos sociales, constituyéndose la relación afectiva y erótica como un vínculo con sentido por sí mismo. Frente a un mundo en ocasiones amenazante, se buscaría el espacio de intimidad como un necesario lugar de refugio (Costa, 2007), un lugar de privacidad alejado de la mirada de otros.

Este espacio de intimidad ha sido definido, según Mailer \& Herrera (2009), como una experiencia 
profunda que implica cierto grado de privacidad y de contacto cercano y cuya pérdida es sentida como una experiencia conducente a un considerable dolor psíquico. La intimidad puede ser también conceptualizada como la mutua exposición del sí mismo (Kohlenberg; Tsai, \& Kanter, 2009). Se trata de una sensación subjetiva de conexión con un otro, resultado de una transacción que consiste en la autorrevelación y en la responsividad con la pareja (Laurenceau, Rivera, Schaffer \& Pietromonaco, 2004). El psiquiatra italiano Pasini (1992) agrega que la intimidad con la pareja no es posible sin la intimidad personal. Se trataría por tanto de un tipo de equilibrio con uno mismo y los demás. Este autor distingue cinco planos en los que puede circular la intimidad: el espiritual, el sexual, psicológico, corporal e intelectual. Podemos decir por lo tanto que la intimidad consiste en el contacto cercano, la privacidad de a dos, o la exposición del sí mismo a través de la reciprocidad, rescatando aquellos elementos de las definiciones anteriores que nos parecen más relevantes.

Este artículo se centra en la dimensión psicológica de la intimidad. Es fruto de una investigación acerca de los significados y la experiencia subjetiva de adultos chilenos acerca de su relación de pareja. Quisimos preguntarnos aquí, entre otras cosas, acerca de cuáles son los sentidos que las personas otorgan hoy a sus relaciones y al hecho de vivir en pareja, así como acerca del lugar del otro en una relación de intimidad. En el marco de las definiciones anteriores, partimos del supuesto que el vínculo de pareja, aunque no el único, era el ejemplo paradigmático de una relación de intimidad.

\section{MÉTODO}

Se realizó un estudio de carácter cualitativo, privilegiando una perspectiva "desde dentro" que enfatizara las subjetividades individuales (Mejía, 2004). Más específicamente, el estudio estuvo enmarcado dentro del Enfoque Biográfico (Legrand, 1993; Sharim, 2005) y utilizó la técnica de los relatos de vida como instrumento de recolección de datos (Lindón, 2000; Sharim, 2005). El Enfoque Biográfico considera cada relato como la narración de una práctica y un significar humanos, tomando en cuenta su subjetividad particular y distintiva. Permite acceder a los hechos objetivos que se han sucedido en la vida de la persona (Villers, 1999), pero también posibilita entender los sentidos que, a través de la narración, la persona da a cada una de sus experiencias, es decir, cómo habita su historia en los planos afectivo, emocional, cultural y social (Correa, 1999). Este enfoque considera también cada historia singular como una posibilidad de acceso a lo social (Ferrarotti, 1983), ya que la narración es también un relato experiencial producido y alimentado a partir de significados socialmente compartidos (Lindón, 2000). Implica una perspectiva clínica para la investigación, en el sentido que propone en la exploración profunda de la singularidad una vía, paradojal, a la dimensión de lo universal. Los casos singulares serían los que permiten acceder a la especificidad de los componentes de problemáticas más amplias que trascienden a cada individuo. Los relatos fueron obtenidos a partir de 3 encuentros con cada uno de los participantes. En el primer encuentro, bajo la consigna inicial "cuéntame acerca de tu historia de pareja”, se buscó abrir la narración y permitir al participante explayarse espontáneamente acerca de este aspecto de su vida, otorgándole libertad para estructurar su relato desde dónde él lo deseara. El segundo encuentro, más directivo, tuvo como objetivo introducir algunas preguntas que permitieran profundizar en aquellos aspectos relevantes para la investigación y aclarar dudas. El objetivo del tercer encuentro fue el de comentar la experiencia de participación y cerrar el proceso. Cada relato fue transcrito y enviado al participante entre un encuentro y otro, como una forma de generar procesos de reflexión. Se recogieron 8 relatos de hombres y mujeres habitantes de la ciudad de Santiago, durante el año 2009. La selección de los participantes se realizó a través de un muestro intencionado de tipo teórico (Flick, 2004) y el contacto con ellos fue realizado a través del método de bola de nieve (Patton, 1990). Los criterios de inclusión de los participantes fueron los siguientes: a) tener entre 25 y 50 años b) pertenecer a niveles socioeconómicos medio y medio alto (según nivel de estudio y lugar de residencia). La elección de estos criterios estuvo orientada por la búsqueda de una mayor diversidad en cuanto a los niveles de individualización social, los que en Chile se han asociado con la edad, el nivel educacional y la pertenencia social de las personas (PNUD, 2002). Se intentó, además una distribución equitativa por sexo, entrevistándose a 4 mujeres y a 4 hombres. A continuación se presenta una descripción general de cada uno de ellos. Aunque la presencia de hijos no constituyó un criterio inicial de inclusión, éste fue un aspecto relevante en el análisis posterior. Por lo tanto, se señala también en la tabla el número de hijos conviviendo en el hogar. 
Tabla 1. Descripción de los participantes

\begin{tabular}{|l|l|l|l|l|l|l|}
\hline Participante & Sexo & Edad & Situación de pareja & Formación & Nivel comuna de residencia & Número de hijos \\
\hline Cecilia & F & 38 & Casada & Técnica & Medio & 2 \\
\hline Alejandra & F & 30 & Casada & Profesional & Medio & 0 \\
\hline Federico & M & 50 & Casado & Profesional & Medio alto & 7 \\
\hline Nora & F & 40 & Separada & Técnica & Medio & 3 \\
\hline Javier & M & 33 & Divorciado & Técnica & Medio & 0 \\
\hline Roberto & M & 40 & Soltero & Profesional & Medio alto & 0 \\
\hline José Luis & M & 36 & Separado & Profesional & Medio & 1 \\
\hline Teresa & F & 37 & Soltera & Profesional & Medio alto & 0 \\
\hline
\end{tabular}

El material recogido fue analizado en dos etapas. Un primer momento, llamado análisis singular, en que cada relato fue analizado en profundidad y en su totalidad por un miembro del equipo. Desde un paradigma interpretativo, se realizó un análisis de tipo hermenéutico de cada narrativa. En este análisis se reconstruyó la historia que recogida, realizando un ordenamiento temático y temporal del material, lo que permitió identificar ejes analíticos y desprender hipótesis de trabajo preliminares particulares para cada caso. Como una manera de incluir la subjetividad de la interacción narrador/entrevistador, la que sostiene y construye el relato (Legrand, 1999), y en la línea de la necesidad de instancias de triangulación en estudios de tipo cualitativo, se incluyó en el análisis singular de los relatos una "tercera persona exterior", que leyera el relato y acompañara el proceso de análisis del relato de vida. Se intentó así un dispositivo que posibilitara un manejo analítico de las vivencias del entrevistador, suscitadas por los relatos y por la identificación que conllevan, poniendo su propia subjetividad al servicio de la investigación. A partir de esto se constituyeron, al interior del equipo de investigación, duplas de trabajo para los análisis singulares de cada relato. Luego, cada análisis singular fue sometido a un proceso de triangulación en el equipo a través de la discusión grupal y puesta en común de las ideas centrales identificadas. Finalmente, en un segundo momento de análisis, el que fue llamado análisis transversal, se incorporó la totalidad de los relatos, extrayendo dimensiones o categorías centrales que permitan visualizar coincidencias o diferencias relevantes en relación al tema estudiado.

\section{RESULTADOS}

Presentaremos aquí los resultados obtenidos en este estudio a través de una síntesis del análisis singular a que fue sometido el relato de cada uno de los casos entrevistados. Esta síntesis recoge lo central de la escucha de cada narrador por parte tanto de la investigadora que recogió la historia como del equipo que participó en su análisis. En otras palabras, corresponde a la historia que reconstruye el equipo de investigadores de lo que cada narrador relató a partir de la consigna que preguntaba por su historia de pareja.

\section{Cecilia: la intimidad que intimida}

Cecilia tiene 38 años y se desempeña a tiempo completo realizando labores administrativas en una empresa de gran tamaño. Vive junto a su marido y a sus dos hijos adolescentes en un sector residencial de clase media de la ciudad de Santiago. Su relato puede ser escuchado como una búsqueda constante por encontrar la calidez de una familia y por lograr un hogar acogedor. Su lucha se plasma en la búsqueda de un lugar físico donde constituir ese hogar, tomando decisiones la mayor parte del tiempo en forma individual y arrastrando a su marido hacia un proyecto más bien personal que de a dos.

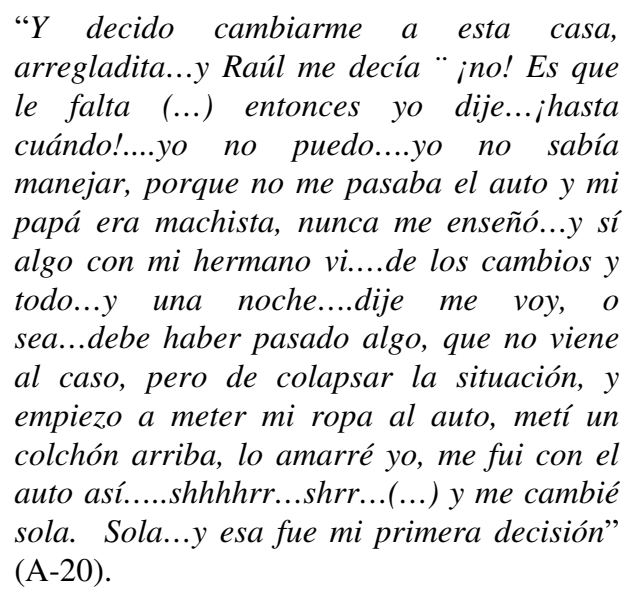

Pero en la búsqueda de este hogar, Cecilia necesita sobretodo de otros que le ayuden a alcanzar su familia ideal. Al casarse, Cecilia parece encontrar al hombre perfecto que la ayudará a encontrar la tranquilidad que tanto busca: los otros parecen ser una vía para lograrlo. Su relación hacia los demás 
no es puramente instrumental. Su marido y sus hijos son importantes y su sentimiento de cariño y amor hacia ellos, genuino. $\mathrm{Su}$ dinámica no tiene elementos que le imposibiliten mirar al otro. Ella es capaz de percibir a los demás como personas significativas, sin embargo, parece establecer una relación de ambivalencia en vínculos de intimidad. Ese es entonces otro aspecto característico del relato de Cecilia: paradójicamente, ella parece necesitar desesperadamente la mirada del otro, el sostén del otro, para poder sentirse tranquila. Necesita a su marido para formar su proyecto personal, pero al mismo tiempo teme a la cercanía con él. La intimidad excesiva la intimida. La figura de otro grande y potente la atemoriza. Ella se convierte entonces en la "gerente" de la familia: es ella quien decide, ella quien lleva a los demás, es ella quien incluso los agrede, especialmente a su marido, a través de sus críticas. La historia de Cecilia es la historia de un logro, pero quizás de un logro acerca de cómo establecer una intimidad no íntima. En su historia de pareja, ella defiende el hogar, ya que el matrimonio "vale la pena", pero su relato no es una historia acerca de una pareja: Cecilia parece hablar de su proyecto de familia, de su proyecto de pareja, pero no de la constitución de una relación de intimidad con otro: "cuesta hablar de a dos".

\section{Alejandra: la intimidad postiza}

Alejandra tiene 30 años y se desempeña en un cargo administrativo de una empresa. Vive con su pareja en Santiago, en una comuna de sector medio, hace cinco años. No tiene hijos. Su relato da cuenta de su gran preocupación de madre de los hijos de su marido que ella denomina como hijos postizos. Pero al mismo tiempo, hay otro eje que va cruzando la narración que se refiere más bien a un discurso que pone límites al esposo, en términos de no aceptar situaciones que ella perciba como potencialmente dolorosas para ella. El relato de Alejandra parece susceptible de dos lecturas simultáneas. Una que se refiere a una mujer "moderna", exigente, pragmática, que no está dispuesta a sufrir por un hombre; que pone condiciones a la relación y que defenderá sus derechos sin transar. Pero al mismo tiempo, contiene elementos de la conflictiva más clásica femenina: ubicada en la pareja principalmente en un lugar de madre, tanto en relación a los hijos de su marido como también respecto a él. La figura de su pareja va delineándose en función de su preocupación por no sufrir y de la manera como ella maneja las situaciones en que se siente expuesta, como es el caso emblemático que él pueda chocar su auto. “...más que nada yo actúo por mi sanidad mental. Si yo encuentro que yo estoy sufriendo, por algo o por alguien, prefiero mil veces apartarlo..." (B-46)

La permanente negociación con su pareja da cuenta también de la preocupación de Alejandra por su autonomía, expresada en sus logros materiales. Una fuente de sufrimiento es la falta que ella detecta en su pareja por ir a la par en este esfuerzo de surgimiento y ascenso social que la caracteriza. Por un lado, ella transmite una relación de pareja con una conflictiva clásica, en la cual ella se posiciona como madre desde el cuidado y la responsabilidad y él aparece infantilizado, irresponsable y con buen humor. Y, por otro, una movilización personal por la autonomía y los logros personales, en función de la cual no trepida en poner sobre la mesa la posibilidad de término de la relación como solución frente a las situaciones de desencuentro. El sentirse independiente, autovalente y exitosa en lo que emprende, le permite sentirse menos vulnerable. En este marco, vivir la intimidad como "postiza" le genera la ilusión de la satisfacción de una importante necesidad de vínculo, pero también la protege del potencial sufrimiento que puede implicar la cercanía afectiva.

\section{Federico: la intimidad predicada}

Federico tiene 50 años y vive con su esposa y sus siete hijos. Ella también es profesional. Viven en un sector acomodado de la ciudad de Santiago. Describe su historia de pareja como una historia de lucha. Se empeña por mencionar que, pese a las dificultades, han enfrentado "como pareja" las vicisitudes de la vida:

\footnotetext{
“(...) siempre acompañado, o sea mi mejor amiga es mi señora, eeh nos llevamos bastante bien aunque (...) discutimos mucho (...) en la vida en pareja eeh, pero siempre por sí mismo hemos sido como compañeros ¿ya? hemos pasado por problemas económicos de pareja, hemos pasado por problemas como pareja, pero siempre lo hemos solucionado todo (...) ¿ya? [en voz baja]" (A-74/78)
}

Federico relata los primeros años como difíciles, totalmente dedicados al trabajo, a sus esfuerzos por obtener una cierta posición profesional, pero también como momentos muy centrados en la construcción de la familia. En relación a esto, llama la atención que en numerosas ocasiones, durante su relato, termina siempre refiriéndose a sus hijos. Parece no poder 
desligar su historia de pareja de ellos, lo que transmite, al mismo tiempo como un proyecto de vida y también como un "esfuerzo".

“... te diría que nuestro mayor esfuerzo es nuestra familia (...) o sea estamos, somos conscientes que nuestro mayor esfuerzo es nuestra familia, y nos hemos dedicado a nuestra familia (...) es como tener una tarea en común (...) o sea yo lo veo como tener una tarea en común, lo veo como un proyecto" (A-328/336)

Federico se refiere al momento actual como de mayor tranquilidad y más centrado en la pareja, ya que los hijos han crecido. Señala que ha sido un trabajo constante y consciente, guiado por su participación en un movimiento religioso que le ha permitido discutir y compartir con otras parejas, y con un sacerdote, los caminos necesarios de recorrer para encontrarse nuevamente con el otro. Este nuevo esfuerzo requiere también de control y del despliegue de una serie de técnicas que lleven a la pareja, en forma rigurosa y planificada, a encontrar espacios de autoconocimiento. De esta forma, la historia de Federico está orientada al deber ser, el que influencia fuertemente su intimidad. Se trata de una intimidad predicada desde una sociedad tradicional y conservadora. Pero, pese a sus esfuerzos, hay algo en él que parece devaluado, disminuido, cansado, algo no logrado. Parece sentirse impotente frente a lo inalcanzable de su autoexigencia de superación permanente. $\mathrm{Su}$ intimidad es excesivamente reglada desde fuera, observada, predicada $\mathrm{y}$ finalmente penalizada ante cualquier intento de descontrol. Pero es precisamente sólo en este relato donde la intimidad aparece con mayor fuerza. Federico se refiere a su pareja en términos amorosos, habla de ella como su compañera, se refiere a un nosotros, dando cuenta de una complicidad y un proyecto común en su relato de la pareja.

\section{Nora: la desilusión de la intimidad}

Nora es una mujer de 40 años, separada con hijos, funcionaria de una institución pública. Actualmente tiene una nueva relación de pareja. Vive en una comuna de clase media de Santiago. Cuando habla de intimidad se refiere a una construida de dos ingredientes: idealización y “deber ser". Nora espera gestos y complicidades de su marido, los cuáles se transforman en una decepción muda que comienza desde la Luna de Miel. Impresiona que ella no da cuenta de intentos por resolver esta temprana desilusión. Pareciera que su deseo de calzar con un modelo más tradicional, encarnado en la voz de la madre, la deja sin posibilidades de enfrentar la realidad de manera creativa y personal. Por ejemplo, Nora se queja de que la madre cree en el matrimonio a cualquier precio. Y ella responde a esta creencia, disimulando sus conflictos matrimoniales y actualmente ocultando su afecto por su nueva pareja. De hecho, se cree constantemente juzgada por su madre, su familia, incluso sus vecinos. Da la impresión de estar atrapada en una norma, una forma "ideal que le impide hacer una construcción de su proyecto de pareja a su manera. A lo largo de las entrevistas ella comienza a identificar lo que de cierta manera no le pertenece.

\begin{abstract}
"La verdad es que no creo en el amor eterno, no creo en el matrimonio para toda la vida, es un concepto..., no sé, de muchos años atrás. Pero si me alcanzó y me atrapó a mí. Entonces, qué pasa, que ese tema marcó mi vida y..., si pudiera vivir de nuevo, si pudiera nacer de nuevo, no, no, para nada, tomaría todo mucho más light, hubiera sufrido menos de todas maneras, hubiera sufrido menos". (B-16)
\end{abstract}

Nora es un ejemplo paradigmático de una mujer latinoamericana atrapada a medio camino entre un discurso más tradicional y otro moderno de libertad y auto gestión. Por una parte, es la clásica mujer que lo "da todo": trabaja y cuida hijos, renuncia al amor de pareja por cuidarlos, deja de vivir como quisiera. Y de manera simultánea, es una mujer que se separa, estudia una carrera, obtiene logros laborales y materiales. Es en el ámbito laboral que cumple con un mandato de mujer moderna y es en el ámbito afectivo que adscribe al modelo tradicional.

\section{Javier: la (des) gracia de la intimidad}

Javier tiene 33 años; estudia y trabaja en Santiago. Está divorciado hace algunos meses y separado hace dos años. Si bien actualmente tiene una pareja, el relato de Javier es el relato de una ruptura, él cuenta la historia de su separación. En su discurso se observa una objetivación del otro, en tanto su mujer pasa a ser un objeto en pugna con la familia de origen:

"Ya dejó de ser su hija, ella decidió casarse conmigo (...) yo no me la robé."(A-216)

El ser su pareja la deja desprovista de su familia, ya no es hija, es su mujer. Es suya, como lo es la casa que él compra cuándo se casan y con la que él se queda luego de la separación. Javier la posee y no está dispuesto a compartirla con nadie. Pero es 
justamente esto lo que no sucede, pues mientras en su discurso su mujer parece suya, en los hechos ella permanentemente no opta ni por él, ni por su matrimonio. Javier se mantiene ciego y sordo a los conflictos, aunque a ratos vislumbra que su matrimonio está muy lejos de lo que él esperaba. Y es en una conversación con otra mujer que Javier descubre lo infeliz que es. Esto da paso a una infidelidad y a una ruptura que se hace irreconciliable.

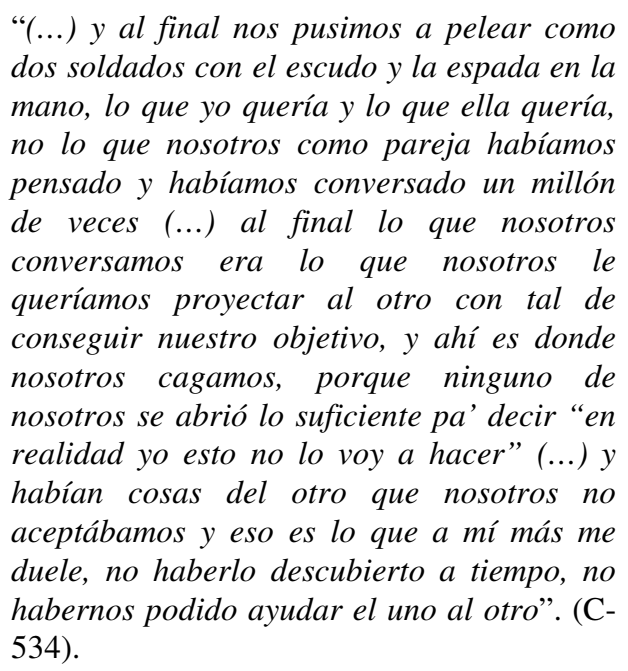

Hay algo de la intimidad que se hace insoportable, algo que remite a cierta pérdida de libertad, esta sensación de estar amarrado a la que alude Javier, y que en su matrimonio se traduce en una sensación de asfixia en la relación con su mujer, justamente es esto lo que atemoriza y finalmente lo distancia del otro.

\footnotetext{
“(...) porque el problema es que tú tenís que estar conmigo y yo contigo, entonces yo no soy así, yo no puedo estar amarrado a alguien todo el día." (B-184)
}

\section{José Luis: la liviana intimidad}

José Luis tiene 36 años; trabaja en un organismo estatal. Nació y estudió en una ciudad del norte de Chile. Vive en Santiago desde que se tituló. Está separado hace pocos años y tiene una hija de 11 años. Vive con su actual pareja hace dos años. Su relato es paradojal, pues al inicio se estructura fuertemente en torno a las dificultades que ha tenido en su vida en las relaciones sociales, lo que le ha causado intensos síntomas ansiosos, y a su manera de sobreponerse a estas dificultades. Pero muy luego, va desplegándose alrededor de una narración muy entusiasta sobre los detalles de sus experiencias con mujeres, como si estas dificultades se hubiesen borrado. José Luis transmite así algo liviano, "light" en sus términos, respecto a la intimidad. Es como si estuviese cerca, pero no estuviera; como si pudiese tener apertura a otro, pero no tuviese; como si hubiese conexión y no la hubiera. Sus relaciones se caracterizan por ser instrumentales, en el sentido que percibe a los otros muy marcadamente de acuerdo a las propias necesidades. Así, por ejemplo, explica que mantuvo su matrimonio sólo por la preocupación que su hija fuese criada en un hogar "bien constituido".

"Como no me satisfacía sexualmente con mi mujer y no quería separarme por mi hija...no me quedaba otra que buscar apoyo externo, te fijai....me metí con mucha mujer" (A-16)

Su relato parece omitir la dimensión más difícil o las contradicciones de toda experiencia humana. Y parece más bien una omisión para sí mismo. Lo conflictivo entonces tiende a resolverlo de manera simple, práctica, considerando criterios similares y homologando decisiones tan distintas como tener un hijo o comprarse un auto. Asimismo, con su pareja actual tiende a repetir este patrón instrumental. Atribuye, nuevamente de manera ligera, las dificultades con ella a su inmadurez o a una brecha generacional. Esta visión la ha ido construyendo desde un lugar que él define como "estudioso" del comportamiento de otros, pero no de sí mismo. Ha desarrollado una suerte de cáscara de adecuación social, sorteando así las importantes dificultades que ha tenido a lo largo de su vida en este plano, focalizándose en aplacar los síntomas angustiosos que estas dificultades le producían, sin entender mayormente lo que le sucedía. La intimidad de esta manera no puede sino ser liviana, ya que la relación con otro es un proceso hermano de la relación íntima consigo mismo.

\section{Roberto: la intimidad como proyecto fallido}

Roberto tiene 40 años. Trabaja en forma independiente. Vive solo en un barrio acomodado de Santiago. Actualmente, se encuentra en una relación de pareja de varios años. Transmite su deseo de tener una pareja, de formar una familia, de llegar a ser padre. Pero el camino de sus relaciones está cargado de vaivenes, pese a sus intentos por mostrar un hilo conductor. Sus relaciones están llenas de dificultades, pero especialmente teñidas por su propio desencanto en relación a sus expectativas de formar una relación "normal". Roberto busca parecerse a un ideal de pareja, en el que cada uno sea capaz de realizar sus propios proyectos, encontrándose luego en un 
proyecto común. Sin embargo, más que un proyecto construido entre dos, es él el que construye una relación, en base a lo que se espera o él cree que se espera. Sus palabras hacen pensar en un mundo de cartón, armado pero frágil, sin una base sólida que le permita conectarse con otro. Roberto incluye a sus parejas en su propia historia, pero sin visualizarlas, sin considerarlas del todo. Pese a una fachada de proyectos negociados, no existe ningún tipo ajuste o de acuerdos en el plano de la intimidad. Incluye a sus mujeres de una forma ficticia; cumple formalmente con incluir, pero en el fondo no lo hace. Se trata de una intimidad que no existe, pero que debe ser "mostrada" dado el mandato social de considerar al otro.

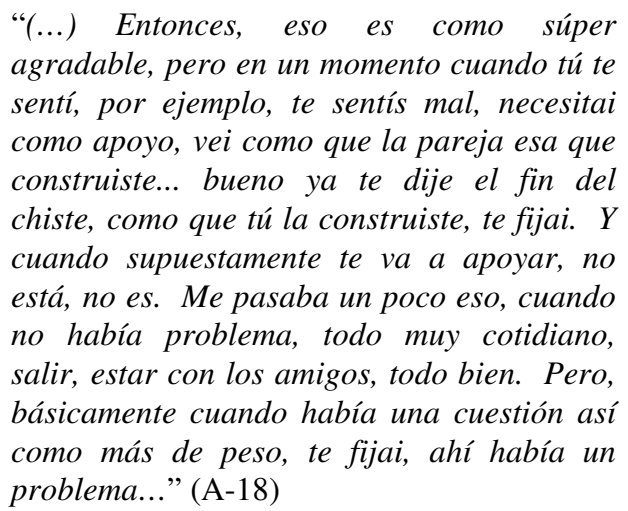

Frente a estas dificultades surge en él la necesidad de controlar cada una de las piezas en la construcción de su pareja. Todo parece estar planeado y racionalizado y se concretiza en la adquisición de bienes materiales. La estabilidad económica, la compra de un departamento y el éxito profesional parecen sostener la relación de pareja. Cabe preguntarse si es éste el verdadero proyecto de Roberto o si con esto responde a las expectativas sociales. Él se relaciona con un mundo más que con una persona, excepto al momento de manifestar su deseo de ser padre. Este deseo se transmite como la única pieza sólida de su historia, lo más cercano al espacio de la intimidad. La historia de pareja de Roberto parece más bien la historia de una identidad frágil, de un proyecto fallido.

\section{Teresa: la intimidad tóxica}

Teresa tiene 37 años, vive sola y no tiene hijos. Se presenta como un ícono de la mujer actual: dedicada a un trabajo absorbente, autosuficiente, preocupada por su desarrollo psicológico y espiritual. Una mujer competitiva, eficiente, que habla fuerte y no se queda callada ante los hombres. Pero esta imagen se fractura en el discurso que Teresa despliega en relación a la pareja. Ella, que es una mujer que ha sabido conducir su vida laboral, en el plano de la pareja parece perder este manejo. $\mathrm{Si}$ bien dice abiertamente que quisiera casarse y tener hijos, despliega un discurso que justifica su soltería. Sostiene así un relato que erige la autonomía e independencia como valor trascendental, en el cual la dependencia tiene un carácter negativo y limitante. Pero esta mujer "actual" sigue deseando lo tradicional: una familia y una pareja. Desea ser madre y le gustaría poder calzar con el modelo de familia trasmitido por sus padres. Este deseo entra en conflicto con su ideal de autonomía e independencia.

\begin{abstract}
"Yo quiero ser mamá, no sé si al final termine siendo mamá. Llevo tanto tiempo sola que no sé. Uno tiene que empezar a desprenderse de sus sueños, porque si no te vas a terminar frustrando. Entonces es como, no sé ya, no sé si encuentre al hombre de mi vida, al príncipe azul, no sé ya." (B-128)
\end{abstract}

En su relato se vislumbra también una intimidad clandestina, oculta. Su lugar en relación a los hombres es ambiguo; mantiene amistades que se confunden con relaciones de pareja, siempre con un tinte poco definido. Es justamente en este lugar donde Teresa encuentra lo "calientito", aludiendo con esta palabra a una cercanía física, sexual, a la complicidad y al compañerismo. Es en el espacio oculto donde Teresa puede acercarse a la intimidad.

\section{ANÁLISIS DE LOS RESULTADOS}

\section{La intimidad como amenaza}

En todas las historias podemos reconocer el lugar de referente que tiene la pareja en la vida de estos narradores, pero dicha referencia no parece implicar la experiencia de intimidad. En hombres y mujeres, la intimidad, como conexión interpersonal y cercanía afectiva, se despliega más en la relación con los hijos y no con sus parejas. El lugar de la pareja en las narraciones no es entonces el de la intimidad. Parece más bien tratarse de un lugar paradojal. Si bien la pareja constituye un punto de referencia en la organización histórica y cotidiana de la propia vida, al mismo tiempo se asocia a una fuente importante de temor y angustia. Estos sentimientos angustiosos tienen que ver, paradojalmente como decíamos, con la amenaza que significa un otro tan cercano como la pareja. En el caso de las mujeres, este temor se asocia principalmente al fantasma de la sumisión a los deseos 
y proyectos del otro. En el caso de los hombres, el miedo está asociado a la devaluación, al sentirse opacado o poco valorado frente a parejas que perciben muy fuertes y dominantes. También a la pérdida de la libertad y la autonomía al estar en una relación de pareja.

Así para Cecilia, quien deposita sus expectativas de una mejor vida en su matrimonio, la experiencia real con su marido le genera una gran angustia y frustración de su proyecto de vida. La distancia, o la no intimidad, parecen protegerla de la amenaza de la dependencia, de quedar sometida a los deseos de él. La distancia, el hacer las cosas por sí misma, frustra sus sueños de una mejor vida, pero le devuelve la fuerza para autosustentarse y desarrollar su proyecto. O Alejandra, quien está permanentemente alerta que su pareja no "le falle", engañándola en cualquier aspecto, obstaculizando así su camino de surgimiento personal. El caso de Federico connota más bien el temor a la devaluación, frente a la figura fuerte y autosuficiente de su mujer. Y en el caso de Javier un temor a ser "amarrado" por su pareja y perder así su libertad. Estar con otro, pero no estar al mismo tiempo. Esta situación que denominaremos a continuación como "monólogo colectivo", parece constituir una forma de sobrellevar esta paradoja, en la que el otro es importante, pero al mismo tiempo amenazante. Estas historias de pareja hablan más bien de un compartir cotidianeidad con la pareja que de una conexión interpersonal íntima. Compartir que por momentos adopta la forma de "co-dirección" empresarial, como si se tratara de dos socios -no siempre afines- tratando de dirigir una empresa.

\section{Monólogo Colectivo}

Uno de los hallazgos que sorprende en este estudio es la impotencia que transmiten los entrevistados para salvar la distancia entre sus expectativas frente al proyecto de pareja y la realidad. De los relatos se desprende que construyen sus ideales de pareja, paradojalmente, de manera individual. Como dice una entrevistada: "me cuesta hacer cosas de a dos". El otro es negado en su condición de sujeto, con sus particularidades y dificultades. Esto explicaría, en parte, la ausencia de herramientas para enfrentar los conflictos. En las historias hay pensamientos, actos desesperados, reclamos, pero poco diálogo. La intimidad por tanto se vuelve elusiva, pendiendo sólo del contacto sexual o de la compra de bienes materiales y muchas veces mediatizada por los hijos. Esta dinámica podría homologarse a un "monólogo colectivo", aludiendo a la etapa de juego infantil, descrita por Jean Piaget
(1962), en que se requiere de un otro cerca, pero sin considerarlo directamente para el juego.

En muchas de las historias los narradores dan cuenta de expectativas que tempranamente no se satisficieron y, sin embargo, nada hicieron al respecto o quizás sí pero de manera solitaria. Frente a la frustración de sus planes y de sus ilusiones en torno a la pareja, se intenta la resolución individual. Si el otro no me da lo que necesito, entonces me autosustento. Una entrevistada, cansada de esperar que su marido se sume al sueño de la casa propia, carga el auto y se cambia de casa sola. Lo sorprendente es que ella no sabía manejar. En este acto tragicómico se muestra algo que también se observa en otros relatos, ante la ausencia de complicidad, ante la imposibilidad de hacer un proyecto de a dos, la pareja se transforma en dos monólogos paralelos. El encuentro de dos proyectos no está generando un tercero compartido, sino, y de aquí el título de este artículo, se coexiste pero no se genera un espacio común. La palabra, la búsqueda del encuentro, la negociación, todos elementos necesarios para establecer relaciones de intimidad aparecen reemplazados por los actos. Hay gritos, embarazos, infidelidades, traiciones y consumo de alcohol que van empeorando la situación y, en la mayoría de los casos, llevando a la ruptura. La mayoría no describe relaciones de complicidad o de mutuo reconocimiento, sino de rivalidad. Los miembros de la pareja aparecen queriendo que el otro se ponga a su servicio, se sume a sus ideales en un desconocimiento de la diferencia con el otro. Hay un permanente enfrentamiento de necesidades que compiten por ser reconocidas, pero cada uno se declara imposibilitado para darle al otro lo que desea. Los relatos nos dan cuenta de relaciones de pareja que podrían definirse como de sujeto a objeto, donde el otro queda situado en un lugar idealizado: el que dará, el que sostendrá, el que sanará las heridas del pasado. Pero es justamente ese lugar el que se constituye como una trampa. El elegido o elegida queda privado de la posibilidad de desplegarse como un otro con defectos, con necesidades, con mezquindades que, por definición, lo alejan del lugar que se le ha otorgado.

\section{Evitando la Diferencia y la Dependencia}

El hecho que la cercanía con la pareja esté connotada de una suerte de amenaza al propio desarrollo, lleva a una evitación de la dependencia. Esta aparece en los relatos como una dimensión más cercana a la idea de sumisión, en el caso de las mujeres, o de devaluación y pérdida de libertad, en el caso de los hombres. Emblemático es el caso de Teresa, quien en su discurso habla de la dependencia 
como una debilidad imperdonable y enarbola la autonomía como el valor fundamental del crecimiento personal, proceso en que el otro podría convertirse en un estorbo. Se trata entonces de una suerte de negación de la dimensión dependiente de una relación, la que es ineludible en tanto parte constitutiva de la tensión propia de una relación entre la independencia y la dependencia. De hecho, la autoafirmación es un proceso psicológico y relacional que nos hace dependientes del otro, se depende de su reconocimiento para permitir, paradojalmente, la sensación de ser uno mismo. Y en forma recíproca, la autoafirmación del otro también requiere de nuestro reconocimiento, tratándose así de un proceso de mutuo reconocimiento (Benjamin, 1998). El reconocimiento del otro implica aceptación o convivencia con las diferencias interpersonales. Sin embargo, se observa en estos relatos que las diferencias están estrechamente asociadas a los conflictos y al sentirse cuestionado, de modo que éstas son evitadas o negadas. Hay por tanto temor a la intimidad, pero paradójicamente, también necesidad de ésta, en cuanto a la definición identitaria. Hay que recordar que la pareja ha sido entendida como una suerte de "refugio" frente a la tendencia posmoderna de una definición relacional del yo (Gergen, 2006), en el sentido de dar una cierta estabilidad o contención frente a la vorágine de las múltiples referencias y relaciones a que se enfrenta un individuo en la conformación de la identidad en el mundo actual.

\section{DISCUSIÓN}

La intención de estudiar la intimidad a través de una relación que nos parecía emblemática como la de pareja, se ve confrontada con resultados que ponen en cuestión dicho supuesto. Al hablar de la pareja, los entrevistados no hablaron de intimidad. Son otros los elementos que ellos pusieron en juego. La vida en pareja estuvo asociada en sus narrativas al proyecto personal, a la historia de la familia de origen, a la parentalidad y al logro material. Nuestros resultados nos hablaron de nuevos ideales de pareja, en muchos casos cargados de elementos pragmáticos y orientados al surgimiento económico $y$, en otros, más bien orientados hacia la creación y sostén de una familia o de un proyecto parental. En ellos, hubo escasa referencia al sentimiento amoroso y a la noción de intimidad. Es como si la cercanía y la intimidad con un otro irrumpiera desestabilizando el proyecto personal o el proyecto personal de pareja, el cual se construye sin dejar espacio para los límites y particularidades que aportaría el otro. Nuestros narradores dan cuenta de una vivencia ambivalente de la intimidad con la pareja. Por un lado, la perciben amenazante de su propia individualidad y por otro, constituye un espacio idealizado de refugio afectivo. La estrategia desplegada frente a esta ambivalencia es la que hemos llamado "monólogo colectivo". La diferencia con el otro y la dependencia que se tenga de éste, potencian la dimensión amenazante de la intimidad con la pareja, pues ambas explicitan que se trata de dos personas en el juego. Si hay dos, hay diferencias y potencialmente también conflictos. Son precisamente los conflictos lo que se quiere evitar a toda costa; como si éstos siempre implicaran una ruptura frente a la cual las personas no tuviesen herramientas para manejarse. Nuestros entrevistados parecen relevar así la dimensión más difícil de la intimidad. Es verdad que se busca y se necesita, pero al mismo tiempo, como lo plantea Pasini (1992) ésta requiere de la capacidad de un vínculo de intimidad con uno mismo y de poder entrar en el mundo de los afectos. Es la demanda de autoconocimiento y de capacidad para pensar con las emociones lo que convierte la intimidad en una experiencia tensionante. Al no existir parámetros externos para el "buen desempeño" de la intimidad, es necesario batallar con la incertidumbre, generando escalas propias. En conclusión, hay una dimensión de intensidad y ambigüedad en la manera en que se define la intimidad que termina por convertirla en una experiencia deseada y al mismo tiempo temida. Si bien compartimos lo planteado por Aboim (2006) respecto a que la autonomía en rigor debiera favorecer la intimidad, ésta no es la realidad que se observa en nuestros entrevistados. En ellos se observa una fuerte tensión en el proceso de autonomía, en el desarrollo de la intimidad consigo mismo, que obstaculiza la intimidad con el otro. Los mandatos socioculturales actuales cuyo mensaje es la libertad de cada uno para definirse a sí mismo, parecen operar de la misma manera que un patrón tradicional, como guión externo a adoptar. Pero esta vez sorprendentemente, tal como plantea Ehrenberg (2000), es la autodefinición la que adquiere carácter de mandato. En nuestros narradores encontramos la necesidad de cumplir con estos mandatos, aun a costa de sí mismos. En otros términos, lo que decimos es que las dificultades en la capacidad de establecer intimidad pueden reconocerse en la relación consigo mismo en cada uno de los narradores y narradoras de este estudio. Lo que evidentemente restringe la posibilidad de establecer un espacio de intimidad con la pareja. Este es reemplazado por una cotidianeidad compartida; como 
ya decíamos anteriormente, una suerte de sociedad de miembros de una misma empresa. Se trataría de una pseudo intimidad; un estar con el otro; pero no estar al mismo tiempo, donde el parlamento de cada uno da cuenta de un monólogo, no de un diálogo, que se despliega en presencia de otro.

El proyecto de pareja se va constituyendo a lo largo del siglo XX como un proceso dialéctico, en el cual se pone en juego la construcción de un "nosotros" y al mismo tiempo se preserva un espacio individual (Singly, 2003). Sin embargo, entre nuestros entrevistados el "ir y venir" entre lo individual y el proyecto de pareja, aparece polarizado hacia lo personal. Incluso cuando dan cuenta de sus expectativas de la vida de a dos, éstas no se compartieron de manera explícita con el otro. Da la impresión de un proceso de "como si" se incluyera al interlocutor, pero es una "conversación" que se hace a solas, en un diálogo imaginario, centrado en las propias expectativas y de manera egocéntrica

Parece así que en estos adultos chilenos, la dificultad no radicaría en una tensión entre el proyecto personal y la pareja, sino que más bien en el proyecto personal en sí mismo. Este proyecto adolece de un carácter propio, singular, aunque, contradictoriamente, responde a un mandato sociocultural cuyo contenido es precisamente la libertad de elegir. Puede pensarse que estas dificultades se relacionan, entre otros con nuestra condición de país latinoamericano en el cual se ha instalado con fuerza la ideología de mercado (Moulián, 2002). Esto ha significado una valoración extrema de la lógica del éxito en todos los planos de la vida. Desde este prisma, cada uno siente la (auto) obligación de cumplir con todas las expectativas que sus distintos papeles generan en términos sociales. Esto termina convirtiéndonos en seres que responden a proyectos diseñados desde fuera, ajenos a la propiedad que cada proyecto personal requiere tener. En este modelo no cabe la intimidad, intimidad que requiere el abrirse, la dependencia, el riesgo. La intimidad no se hace en solitario, no se puede autogestionar. No es posible en el marco del pragmatismo del logro y la eficiencia. La intimidad sólo puede materializarse, siguiendo a Benjamin (1998) sobre la base del reconocimiento mutuo, es decir en el marco de la diferencia y de relaciones de sujeto a sujeto. Nuestros narradores nos alertan de un mundo en que la exigencia por cumplir con la demanda postmoderna de "hazte a ti mismo" consume en su consecución una noción más plena del otro. Por lo tanto, nos atrevemos a decir que cuando el otro es restado de su condición de sujeto, se obtendrá como resultado que el diálogo aparente corresponde más bien a monólogos en paralelo.

Por último, no quisiéramos finalizar esta discusión sin hacer mención a algunas posibles restricciones metodológicas, llamando así a cierta cautela al momento de considerar y, especialmente de universalizar, lo anteriormente señalado. Las interpretaciones que presentamos y discutimos no sólo se apoyaron en un número pequeño de casos, sino que también en dos o tres encuentros con cada participante. Si bien creemos que el método de trabajo utilizado nos permitió capturar con gran riqueza algunos aspectos de lo social encarnados en cada una de las historias singulares, se hace necesario también considerar que cada narrativa contiene en sí misma elementos propios de la historia particular de cada participante, influenciados, entre otras cosas, por experiencias propias de cada fase del ciclo vital. Un número mayor de encuentros nos hubiera tal vez permitido acceder a éstos y a otros elementos que nos permitieran aprehender de manera aún más exhaustiva e integrada la dimensión subjetiva de la intimidad en la relación de pareja.

Asimismo, es siempre interesante considerar las limitaciones que implica la utilización de técnicas de producción de datos que interrogan de forma individual a uno de los miembros de la pareja en relación a la historia conyugal. Lo anterior restringe de alguna manera la posibilidad de acceder a otras formas de comunicación no verbales o analógicas presentes en el proceso interaccional, lo que se hace posible a través de diseños metodológicos que contemplen el entrevistar a ambos miembros de la pareja en forma conjunta.

\section{REFERÊNCIAS}

Aboim, S. (2006). Conjugalidade, afectos e formas de autonomia individual. Análise Social, XLI(180), 801-825.

Aboim, S. (2009). Da pluralidade dos afetos. Trajetórias e orientacoes amorosas nas conjugalidades contemporâneas. Revista Brasileira de Ciencias Sociais, 24(70), 107-122.

Ariès, P. (1973). L'enfant et la vie familiale sous l'Ancien Régime. Paris : Seuil.

Beck, U., \& Beck-Gernsheim, E. (2003). El normal caos del amor. Barcelona: Paidós.

Benjamin, J. (1998). The Bonds of Love: Psychoanalysis, Feminism, $\&$ the Problem of Domination. New York: Pantheon Books.

Bozon, M. (2010). Sociologie de la sexualité (2 $2^{\text {èe E}}$ Édition). Paris : Armand Colin.

Correa, R. (1999). La aproximación biográfica como opción epistemológica, ética y metodológica. Proposiciones, 29, 35-44. 
Costa, S. (2007). Amores fáciles. Romanticismo y Consumo en la Modernidad Tardía. Apuntes de Investigación, 012(10), 205-222

De Cristóforis, O. (2009). Amores y parejas en el siglo XXI. Buenos Aires: Letra Viva.

Ehrenberg, A. (2000). La Fatiga de Ser Uno Mismo. Depresión y Sociedad. Buenos Aires: Eds. Nueva Visión.

Ferrarotti, F. (1983). Histoire et histoires de vie. La méthode biographique dans les sciences sociales. Paris: Librairie des Méridiens.

Flick, U. (2004). Introducción a la investigación cualitativa. Madrid: Ediciones Morata.

Gergen, K. (2006). El yo saturado. Dilemas de identidad en el mundo contemporáneo. Barcelona: Paidós

Giddens, A. (1992). La transformación de la intimidad. Sexualidad, amor y erotismo en las sociedades modernas. Madrid: Cátedra.

Kohlenberg, R. J., Tsai, M., \& Kanter, J. W. (2009). What is functional analytic psychotherapy? In M. Tsai, R. J. Kohlenberg, J. W., Kanter, B., Kohlenberg, W. C. Follette, \& G. M. Callaghan (Eds.), A guide to functional Analytic Psychotherapy. Awareness, courage, love and behaviorism (pp. 1-19). New York: Springer.

Laurenceau, J. P., Rivera, L. M., Schaffer, A., \& Pietromonaco, P. R. (2004). Intimacy as an interpersonal process: Current status and future directions (p. 61-78). In D. Mashek, \& A. Aron (Eds.), Handbook of closeness and intimacy. Mahwah, NJ: Lawrence Erlbaum.

Legrand, M. (1993). L'approche biographique. Paris: Desclée de Brouwer.

Legrand, M. (1999). La contra-transferencia del investigador en los relatos de vida. Proposiciones, 29, 115-121.

Lindón, A. (2000). El enfoque biográfico como aproximación a la identidad persona y la negociación de la conyugalidad. Revista Mexicana de Sociología, 62(1), 101-121.

Lipovetsky, G. (2000). La era del vacío: Ensayo sobre el individualismo contemporáneo. Madrid: Ed. Anagrama.

Luhmann, N. (1985). El amor como pasión. Barcelona: Península.
Mailer, S., \& Herrera, E. (2009). Espiar o Intimar. Revista Chilena de Psicoanálisis, 26(1), 58-64

Mejía, J. (2004). Sobre la investigación cualitativa. Nuevos conceptos y campos de desarrollo. Investigaciones sociales, 13, 277- 299.

Moreno, C. (2008). Nuevas (y viejas) configuraciones de la intimidad en el mundo contemporáneo: amor y sexualidad en contextos de cambio societal. In K. Araujo, \& M., Prieto (Eds.), Estudios sobre sexualidades en América Latina (pp. 43-58). Quito: FLACSO Ecuador.

Moulián, T. (2002). Chile actual: Anatomía de un mito. Santiago de Chile: LOM

Pasini, W. (1992) Intimidad. Más allá del amor y del sexo. Buenos Aires: Paidós

Patton, M. Q. (1990). Qualitative Evaluation and Research Methods. Newbury Park, C. A: Sage

Piaget, J. (1962). Play, dreams and imitation in childhood. New York: The Norton Library.

PNUD (Programa de las Naciones Unidas para el Desarrollo) (2002). Informe de desarrollo humano en Chile: nosotros los chilenos, un desafio cultural. Chile: PNUD.

Sharim, D. (2005). La identidad de género en tiempos de cambio: una aproximación desde los relatos de vida. Psykhe, 14(2), 19-32.

Singly, F. de (2003). Intimité conjugale et intimité personnelle: à la recherche d'un équilibre entre deux exigences dans les sociétés modernes avancées. Sociologie et sociétés, 35(2), 79-96. Recuperado em 10 de agosto, de 2011, de http://id.erudit.org/iderudit/008524ar.

Singly, F. de (2005). Le soi, le couple et la famille. Paris: Armand Colin.

Villers, G. (1999). La historia de vida como método clínico. Proposiciones, 29, 103-114.

Recebido em 11/06/2010

Aceito em 01/11/2011
Endereço para correspondência:
Dariela Sharim. Escuela de Psicología, Pontificia Universidad Católica de Chile. Campus San Joaquín. Vicuña Mackenna, 4860, Macul,- Santiago, Chile.E-mail: dsharim@uc.cl. 